\title{
High Temperature Sintering and Oxidation Behavior in Plasma Sprayed TBCs [Single Splat Studies] Paper 1 -Role of Heat Treatment Variations
}

\author{
Swarnima Deshpande \\ Center for Thermal Spray Research, Department of Materials Science and Engineering, State University of New York at Stony Brook, \\ New York, USA. \\ Email: swarnima_d@yahoo.com
}

Received December $1^{\text {st }}$, 2012; revised December 31 ${ }^{\text {st }}$, 2012; accepted January $7^{\text {th }}$, 2013

\begin{abstract}
The TBC system is examined with regards to its response to thermal exposure at high temperature. It has been established before that the thermally grown oxide (TGO) layer that forms upon bond coat oxidation is the key factor determining the performance of the TBC system and/or its failure. However, characteristics of TGO growth, bond coat rumpling, principles governing failure of TBC systems and the various failure mechanisms have been studied extensively in case of just super alloy with bond coat or with thick top coating. In this study super alloy/bond coat system with single splats of YSZ instead of thick topcoat is analyzed in order to scrutinize the effect on the first layer of splats during thermal exposure. The splats with microcracks are the building blocks of the top coat. The most important aspect of this layer is the inherent inter-splat and intra-splat porosity which undergoes sintering during thermal exposure. The interactions between the YSZ splats and the evolving TGO is directly linked to the presence or absence of bond coat oxidation. Therefore the high temperature behavior of this system is analyzed with variations in heat treatment involving, temperature, duration and environment of thermal exposure.
\end{abstract}

Keywords: TBC; Bond Coat; Top Coat; Thermal Exposure; Vacuum Environment; Oxidation; TGO Imperfections; Sintering

\section{Introduction}

Thermal barrier coatings (TBCs) are employed in the aerospace and power systems because they permit the usage of higher operating temperatures and reduced cooling air requirements and yet achieve higher efficiencies and longer engine life thus providing high ripple effects on energy conservation. High service temperatures, extreme and cyclic stresses and harsh environmental conditions are some of the concerns [1]. They experience diverse thermal histories which could be just isothermal exposure or multiple thermal cycles depending on the application [2].

The TBCs are a system consisting of a superalloy substrate, an MCrAlY bond coat (BC)and a YSZ top coat I(TC) applied on these.A thermally grown oxide (TGO), typically $\alpha$-alumina, is formed during heat treatment and/or in service between the bond coat and the topcoat [3]. The bond-coat alloy is an $\mathrm{Al}$ reservoir, enabling $\alpha$-alumina to form in preference to other oxides.

The failure mechanisms involve the TGO, the TGO/BC interface and the TBC. It has been surmised that these mechanisms are activated primarily by the stress state caused by the residual compression in the TGO even when the failure occurs in the TBC layer itself.

The TGO is subject to thickening, as well as an elongation strain associated with new oxide formation on the internal grain boundaries [4]. Studies show that thickness of TGO increases with thermal exposure and induces the strain energy for the crack propagation during spallation [3]. Numerous studies have been conducted to assess the evolution of this bond coat oxidation during thermal exposure of TBC systems [5-9]. Factors during HT that affect durability have been considered [3,10]. Under isothermal HT, the TGO yields and the stress remains at yield, such that all of the growth strain results in thickening of TGO without elongation. Conversely cycling, introduces additional growth strain with associated elongation of the TGO that undergoes cyclic enlargement. Inherent surface roughness of plasma sprayed bond coats i.e. preexisting undulations in the film initiate TGO instabilities which manifest as regular, (relatively) long wavelength undulations, referred to as "rumpling" or localized penetration of the TGO into the bond-coat, in the 
presence of a TBC layer, referred to as "ratcheting". TGO growth and TGO instabilities influence TBC behavior and failure. Effect of rumpling on TBC layer, if present, is observed to be a delamination between TGO and topcoat leading to subsequent failure [9].

However, characteristics of TGO growth, bond coat rumpling, principles governing failure of TBC systems and the various failure mechanisms have been studied extensively in case of just superalloy with bond coat or with thick top coating $[7,8]$.

In this study superalloy/bond coat system with single splats of YSZ instead of thick topcoat is analyzed. The objectives are:

- Understanding the influence of present YSZ layer on the chemistry of bond coat oxidation.

- Studying the interactions between the YSZ splats and the evolving TGO.

- Inspection of effects of bond coat oxidation on first splat layer of topcoat. Single splats as opposed to freestanding coatings include the splat/substrate interfacial interaction. The morphological changes and sintering of intrasplat cracks in the YSZ is directly linked to the presence or absence of bond coat oxidation.

\section{Experimental Approach}

NiCrAlY coatings were air plasma sprayed onto Inconel 718 superalloy substrates. The surfaces of these substrates were then polished to a 0.05 micron finish using a Buehler semi-automatic polisher. Single splats of YSZ were collected on these bond coat surfaces in order to conduct thermal exposure studies on the same. Splats were collected on polished bond coat surface so as to eliminate ratcheting instabilities that could arise due to initial undulations on BC/TBC interface.

Processing conditions used for the NiCrAlY bond coats and the YSZ splats are given below in Tables $\mathbf{1}$ and 2 respectively.

Thermal exposure behavior of these splats in air was studied using a Thermolyne 1400 box furnace, to see effect of temperature and duration. Temperatures used were in the range of $1100^{\circ} \mathrm{C}$ to $1300^{\circ} \mathrm{C}$ and durations were 2 to $24 \mathrm{hrs}$. Only isothermal heat treatments were employed to eliminate cyclic TGO elongation effects. Long-term exposure to high temperature is thought to reduce mismatch stress in the bond coat by relaxation and creep [Ref. from 9] thus resulting in a very long rumpling wavelength and making it impossible to observe the rumpling process. As such for this single splat study, shorter exposure times were considered for isothermal heat treatments to avoid complete spallation or failure.

Particular splats were identified and the top surface microstructures before and after HT were compared to
Table 1. Deposition parameters for APS sprayed NiCrAIY bond coat.

\begin{tabular}{cc}
\hline Gun & Sulzer F4MB \\
\hline Gun voltage & $68 \mathrm{~V}$ \\
Gun current & $500 \mathrm{~A}$ \\
Primary gas (Ar) & $50 \mathrm{SLPM}$ \\
Secondary gas $\left(\mathrm{H}_{2}\right)$ & $10 \mathrm{SLPM}$ \\
Carrier gas(Ar) & $3 \mathrm{SLPM}$ \\
Spray distance & $120 \mathrm{~mm}$ \\
Powder Feed rate & $40 \mathrm{~g} / \mathrm{min}$ \\
\hline
\end{tabular}

Table 2. Deposition parameters for APS sprayed YSZ splats [Metco 204NS].

\begin{tabular}{cc}
\hline Gun & PT-F4MB \\
\hline Gun voltage & $65 \mathrm{~V}$ \\
Gun current & $650 \mathrm{~A}$ \\
Primary gas (Ar) & $40 \mathrm{SLPM}$ \\
Secondary gas $\left(\mathrm{H}_{2}\right)$ & $8 \mathrm{SLPM}$ \\
Carrier gas $(\mathrm{Ar})$ & $3 \mathrm{SLPM}$ \\
Spray distance & $100 \mathrm{~mm}$ \\
Powder Feed rate & $10 \mathrm{~g} / \mathrm{min}$ \\
Gun traverse speed & $10 \mathrm{~mm} / \mathrm{sec}$ \\
Substrate rotational speed & $160 \mathrm{rpm}$ \\
\hline
\end{tabular}

see changes in crack network, surface roughness, and splat lifting/spalling. A comparison of splat cross-sections was made using SEM (Leo 1550, FEG) to observe splat dimensions, microcrack sintering and effect of TGO growth after HT. Back-scattered imaging was employed and Energy Dispersive Spectrometry (EDS) gave elemental composition. Atomic Force Microscopy (AFM) was employed to quantify surface roughness of splats.

Cross-section (CS) samples were prepared by covering the single splats with glass slide, Figure 1, and then polishing using the SEM T-tool of the tripod polisher.

\section{Results and Discussion}

The sintering study of single splats on bond-coat is important because in case of single splats the factors introduced by TBC coating are minimal and failure can be more related to the bond-coat chemistry and microstructure which upon thermal exposure changes by interdiffusion with the substrate and upon thickening of the thermally grown oxide (TGO). The appearance of failure and sites of failure can be determined more stochastically [11].

Single splats of YSZ sprayed onto polished surfaces of 


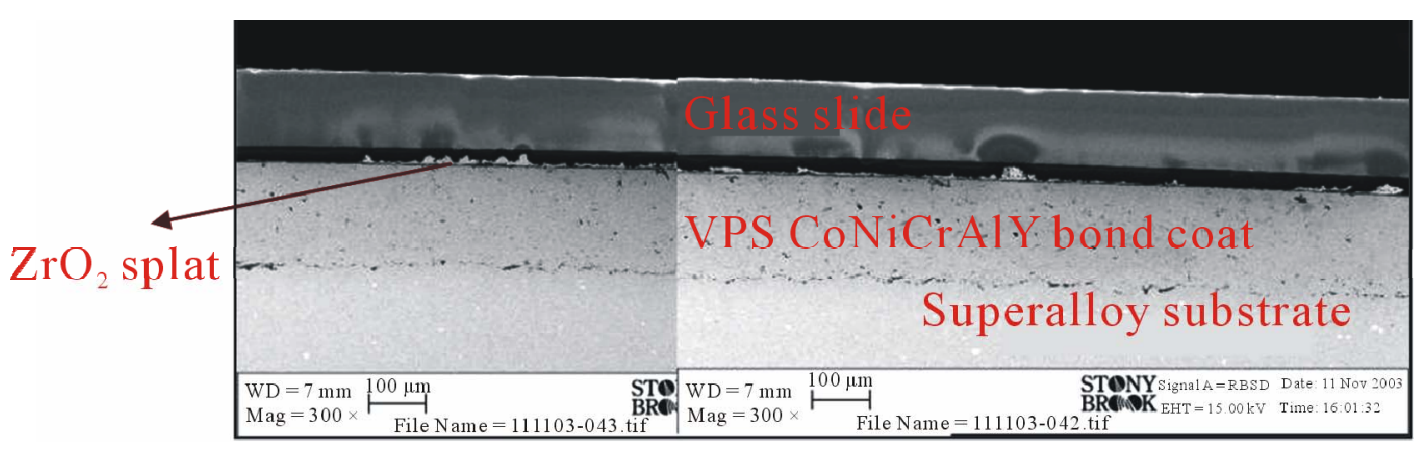

Figure 1. Cross-section sample preparation of single splats on bond coat surface.

MCrAlY bond coats were subjected to various heat treatments. Their top surface microstructures and cross-sections were analyzed before and after Heat Treatment (HT) as described in the previous section.

In order to understand the influence of TGO growth and thickening on the first layer of splats, this system of splat-bond coat-substrate was thermally exposed to different temperatures and for different durations.

\subsection{TGO Growth-Effect of Heat Treatment Temperature}

YSZ splats on bond coated substrate were subjected to a 2 hr heat treatment in air (isochronal) at different temperatures: $1100^{\circ} \mathrm{C}, 1200^{\circ} \mathrm{C}$ and $1300^{\circ} \mathrm{C}$. Particular splats were identified and their top surface microstructures, at exact locations, in the as-sprayed and heat treated condition are shown in Figures 2(a)-(c) for the three temperatures respectively.

In Figure 2(a), it is seen that after $\mathrm{HT}$ at $1100^{\circ} \mathrm{C}$, the overall crack network between the as-sprayed and the heat treated splat seems unchanged. The grain size does not seem to have altered either.

According to Figure 2(b), after $\mathrm{HT}$ at $1200^{\circ} \mathrm{C}$, the assprayed and heat-treated splats still show same overall crack network. However, some outward oxide growth from the bond coat is now visible at the larger microcracks as shown by the circle marks. Finer microcracks have also started sintering as indicated by the arrows.

These effects are even more pronounced after the $1300^{\circ} \mathrm{C} \mathrm{HT}$, Figure 2(c).

More of the fine microcracks are seen to have sintered and the entire microcrack network is now lined with the oxide growth from below. These grains growing outward through the microcracks were analyzed using EDS and indicated $\mathrm{Ni}$ and $\mathrm{O}$ peaks. These phenomena are schematically illustrated in Figure 3.

\subsubsection{NiO Outgrowth Outlining Crack Network on Splat Surface}

APS NiCrAlY bond coat microstructure (Figure 4) contains internal oxide chunks of alumina. These regions may be locally depleted of aluminum. Microcracks in splats are seen to coincide with oxide points in the bondcoat, Figure 4.

Several studies have shown that oxygen diffusion through TGO along grain boundaries causes more TGO growth at these boundaries $[4,5,8]$. Similarly at these microcrack positions, there is a path for oxygen to reach a BC area that is locally depleted of free aluminum. As such, other oxides could form at these microcrack positions.

\section{Supporting Observation}

In some circumstances, as activity of Oxygen at the interface increases, the solubilities of $\mathrm{Ni}$ and $\mathrm{Cr}$ (and $\mathrm{Fe}$ when present) in the $\mathrm{Al} 2 \mathrm{O} 3$ also increase. This condition can result in outward diffusion of cations through the TGO. Upon encountering higher oxygen activities, these cations can form new oxide phases. For e.g. in regions between the TGO and the TBC, the thermodynamics and kinetics are such that spinel formation is allowed [8].

\subsubsection{Sintering of Fine Microcracks}

A study by Thompson et al. speculates regarding subprocesses occurring at a splat level during sintering, as shown in Figure 5. The as-sprayed microstructure (a) incorporates three types of pores. Stage I (b) involves healing of interlamellar porosity, where the separation in the material is very small. While at longer times and at higher temperatures, Stage II (c) occurs by micro-crack healing [3].

Since we are dealing with single splats, we cannot observe the stage I sintering. But incidences of sintering of finer microcracks are seen to increase as HT temperature increases. This is in agreement with the observation of the above study.

\subsection{TGO Thickening-Effect of Heat Treatment Duration}

YSZ splat samples were subjected to an isothermal heat treatment in air at $1100^{\circ} \mathrm{C}$ for different durations: $2 \mathrm{hr}, 8$ hr and $24 \mathrm{hr}$. Figure 6 shows thermally grown oxide 

Paper 1-Role of Heat Treatment Variations
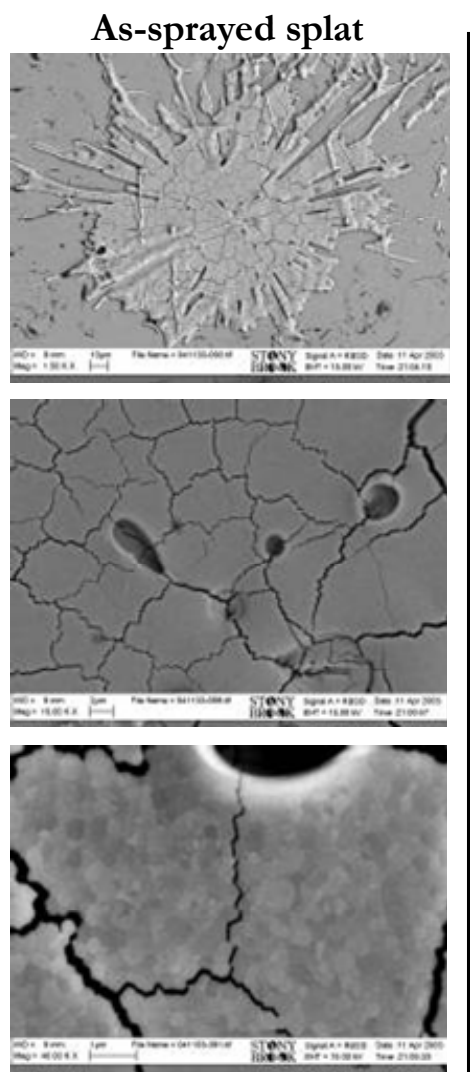

(a)

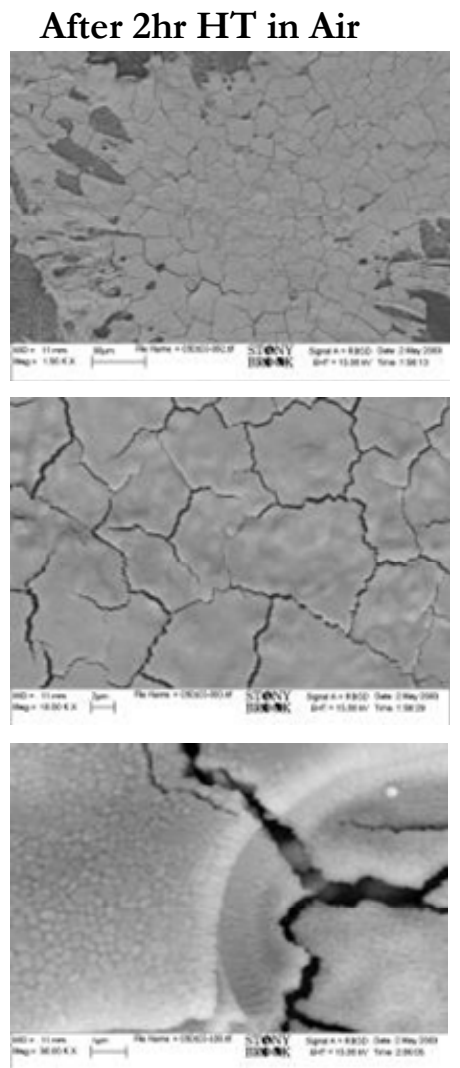

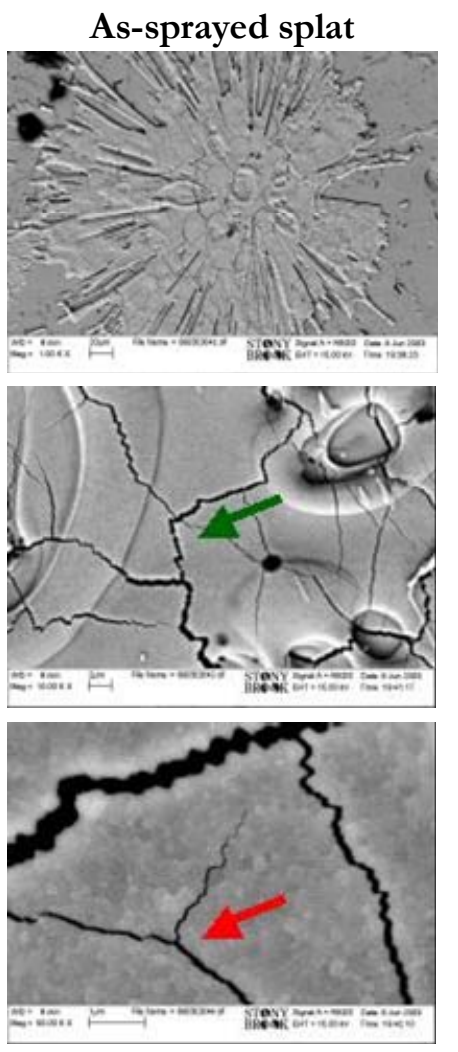

After 2hr HT in Air

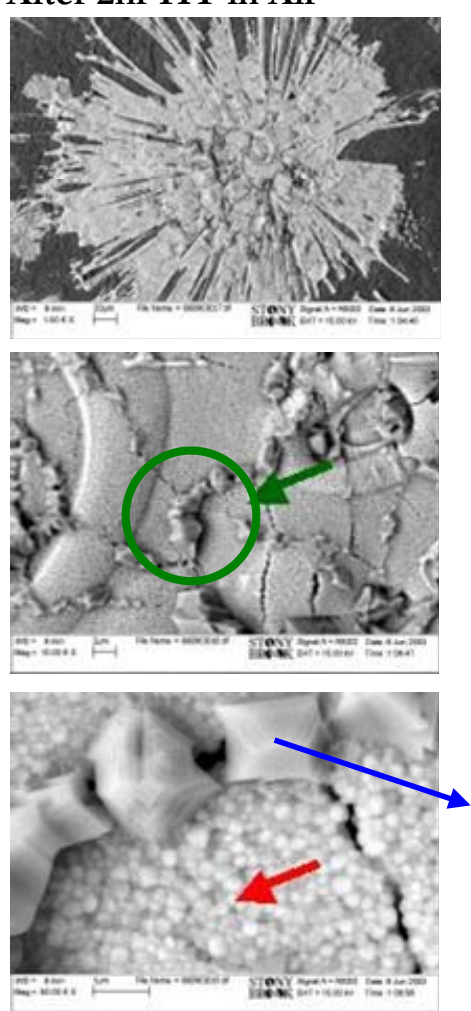

(b) 

Paper 1-Role of Heat Treatment Variations
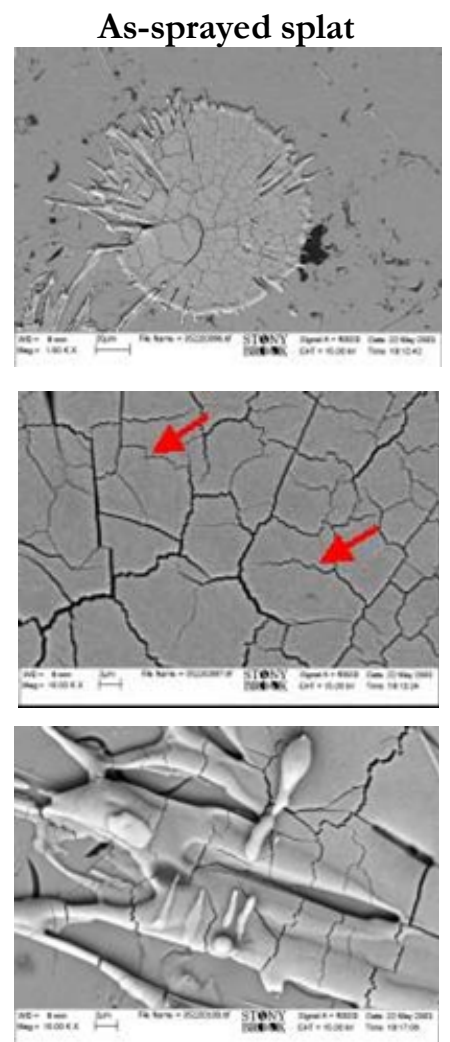

After 2hr HT in Air
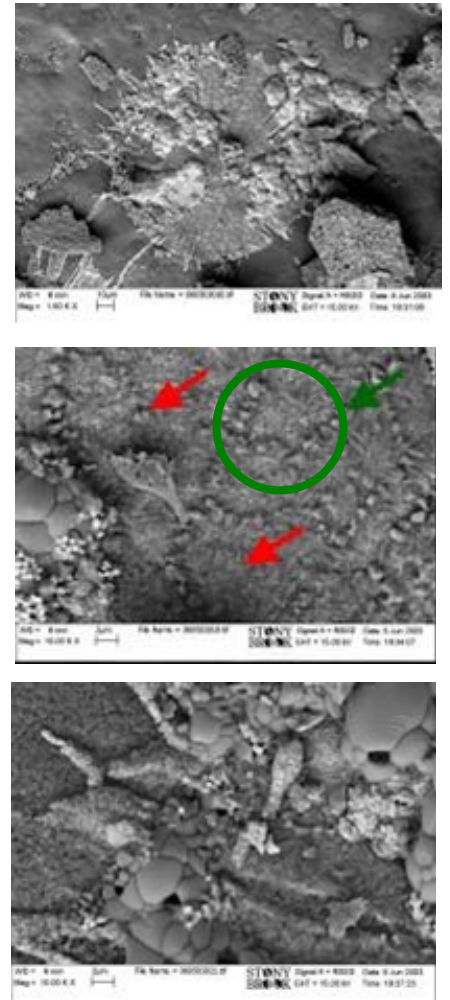

(c)

Figure 2. (a) Splat exposed to $1100^{\circ} \mathrm{C}$; (b) Splat exposed to $1200^{\circ} \mathrm{C}$; (c) Splat exposed to $1300^{\circ} \mathrm{C}$.

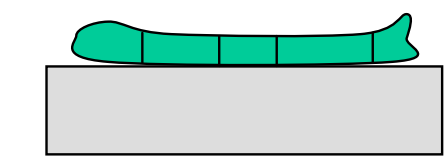

Oxide growing out

of microcracks

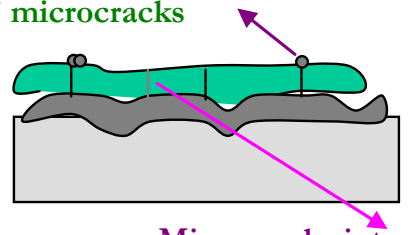

Microcrack sintering

Figure 3. Isochronal HT in air-effect of temp (schematic).

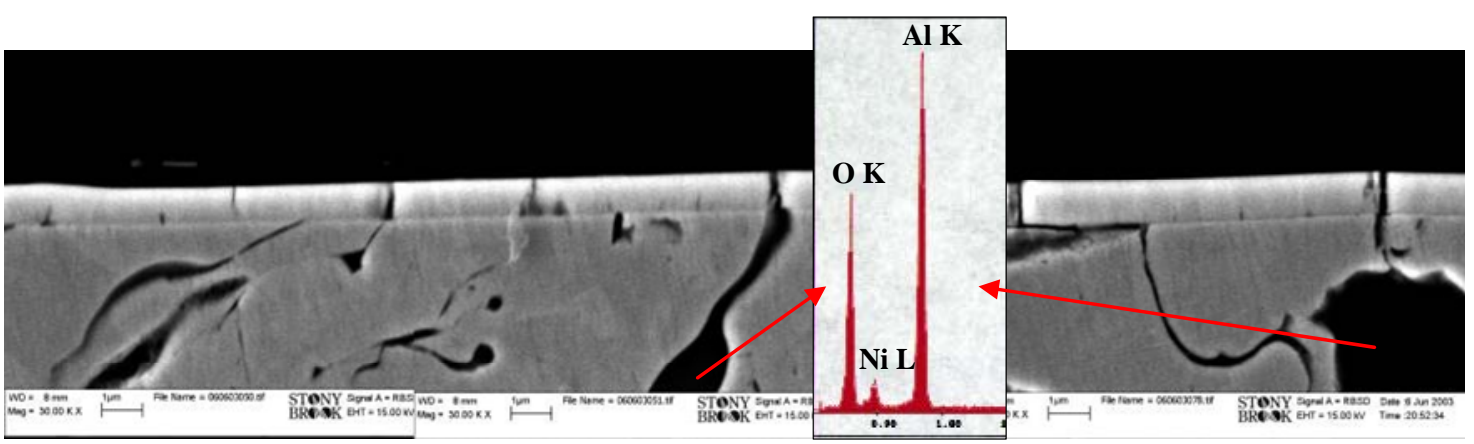

Figure 4. Microcracks coinciding with oxide points. 

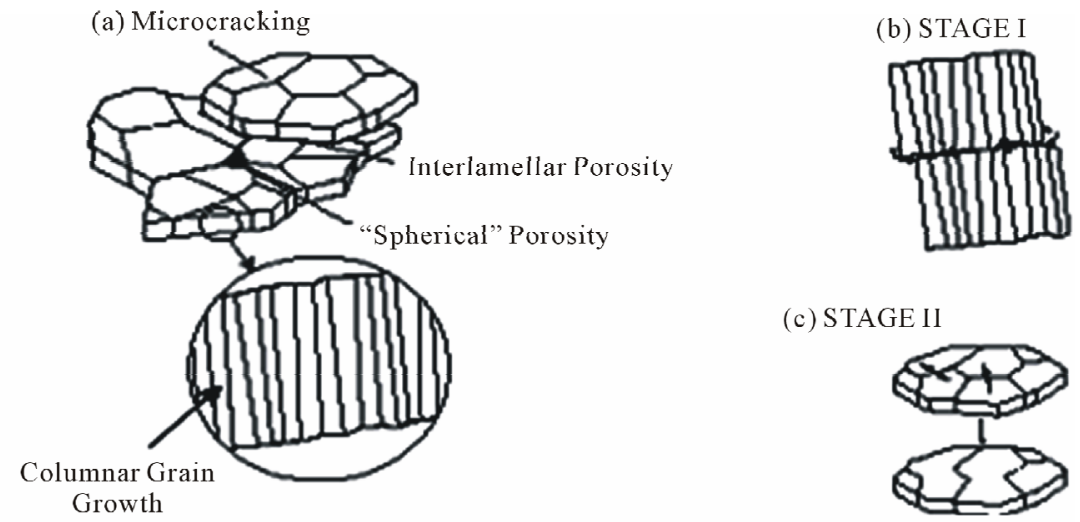

Figure 5. Schematic representation of the proposed sintering mechanism occurring at high temperature [Ref 3: J. A.Thompson, W. Ji, T. Klocker and T. W.Clyne].

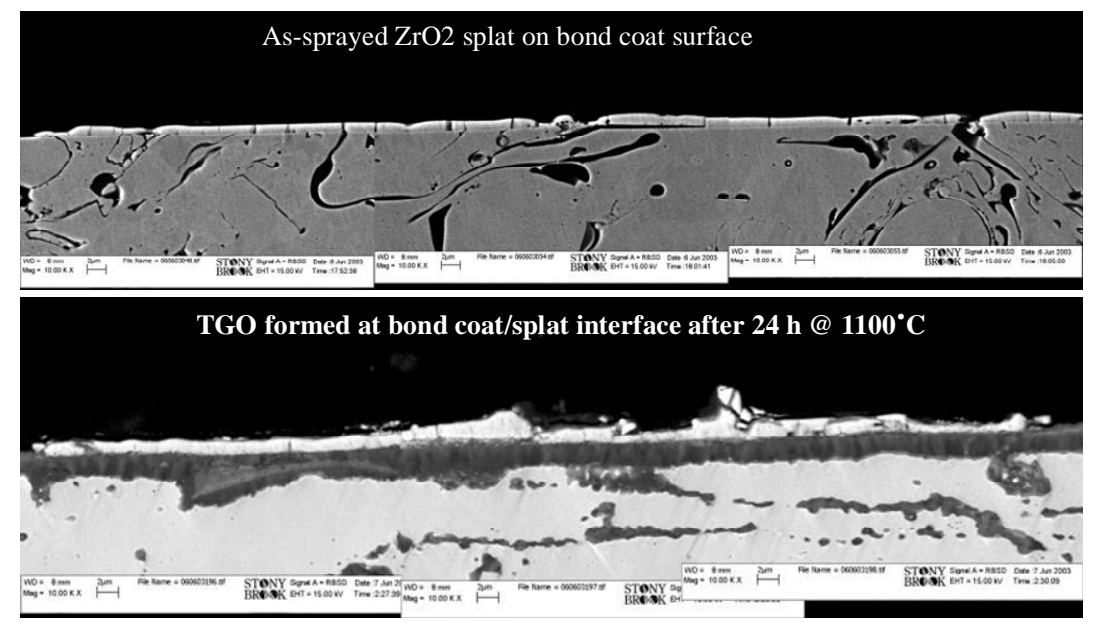

Figure 6. Interface between bond coat and $\mathrm{ZrO}_{2}$ splats (shown as composite images).

layer formed at the interface between bond coat and top coat after $24 \mathrm{hr}$ HT in air.

Splats are imaged at particular locations and their top surface microstructures in the as-sprayed and heat-treated condition are compared in Figures 7(a)-(c) for the three HT times respectively.

Figure 7 (a) shows that after a $2 \mathrm{hr} \mathrm{HT}$ at $1100^{\circ} \mathrm{C}$ the overall crack network has not changed significantly. The columnar grains in the splat appear to have been pushed slightly upwards in some areas. Such regions are marked by square marks.

As seen in Figure 7(b) below, after an $8 \mathrm{hr} \mathrm{HT}$, the microcrack network still remains unchanged between the as-sprayed and the heat-treated splats. Most of the fine microcracks are also still present. However the top surface of the heat-treated splat appears much rougher compared to the top surface of the as-sprayed splat. Square marks denote this roughening. This has been quantified using Atomic Force Microscopy (AFM). Wave patterns depicting the roughness are obtained using section analysis. Mean Roughness analysis over a given area measures the value of roughness as $\mathrm{Ra}=12 \mathrm{~nm}$ for the as-sprayed splat surface and $\mathrm{Ra}=153 \mathrm{~nm}$ for the heat-treated splat surface. Apart from this, top surface as well as crosssection images show a few instances of oxide growth through microcracks (circle marks) as described in the previous section.

From Figure 7(c) below, it is seen that even a $24 \mathrm{hr}$ $\mathrm{HT}$ at $1100^{\circ} \mathrm{C}$ does not cause the overall microcrack network to change or fine microcracks to sinter. More instances of outward oxide growth as marked by circle marks are now visible even at $1100^{\circ} \mathrm{C}$ because of longer HT duration. Thus this outward oxide growth is enhanced by an increase in HT temperature as well as an increase in duration of HT.

Once again splat surface after HT becomes rougher because of lifting of columnar grains in some regions. An examination of cross-section samples revealed that this is probably due to oxide growth over the bond coat (TGO) and its thickness imperfections.

A comparison of Figures 7(a)-(c) shows how the TGO thickness gradually increases with HT duration. This 

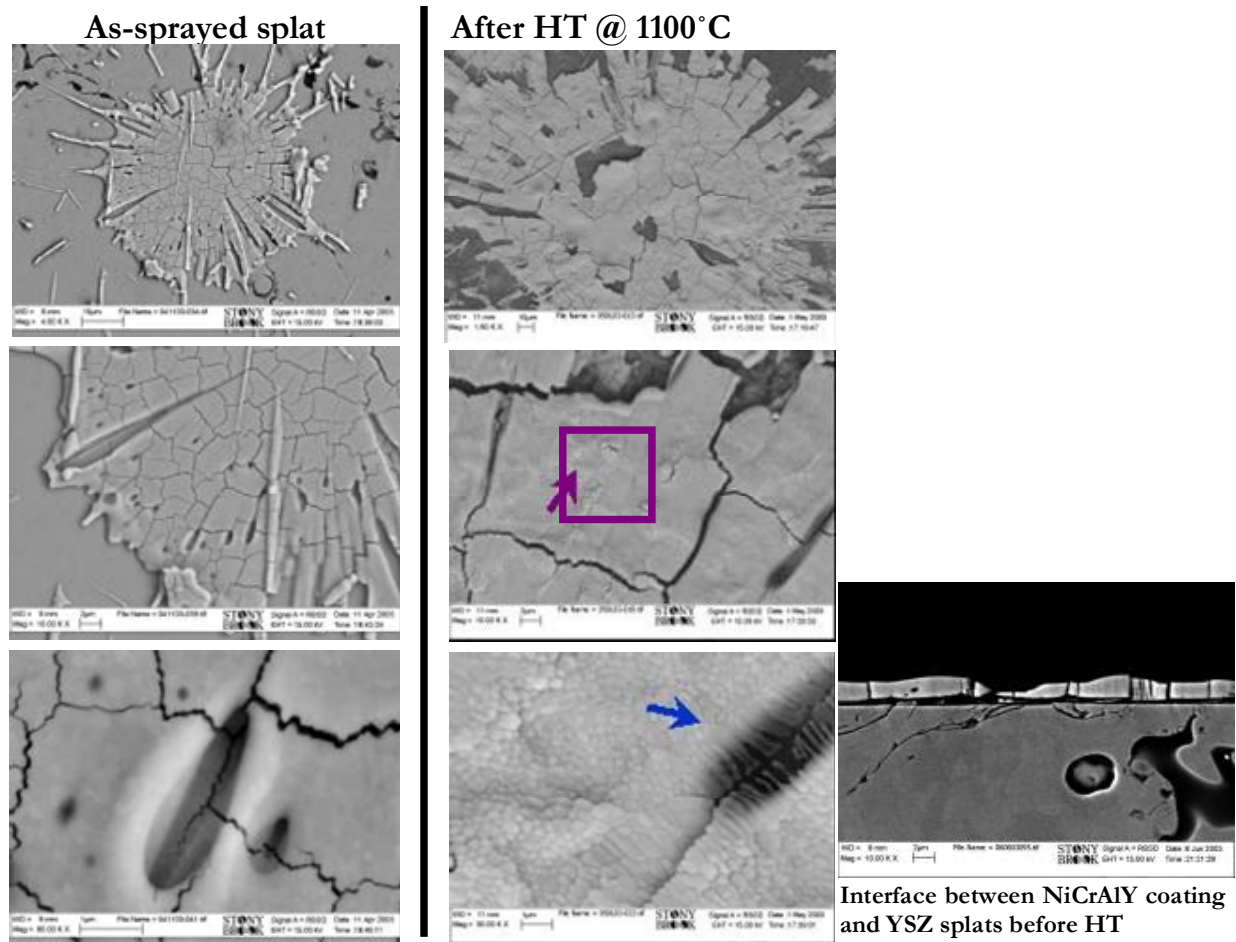

(a)
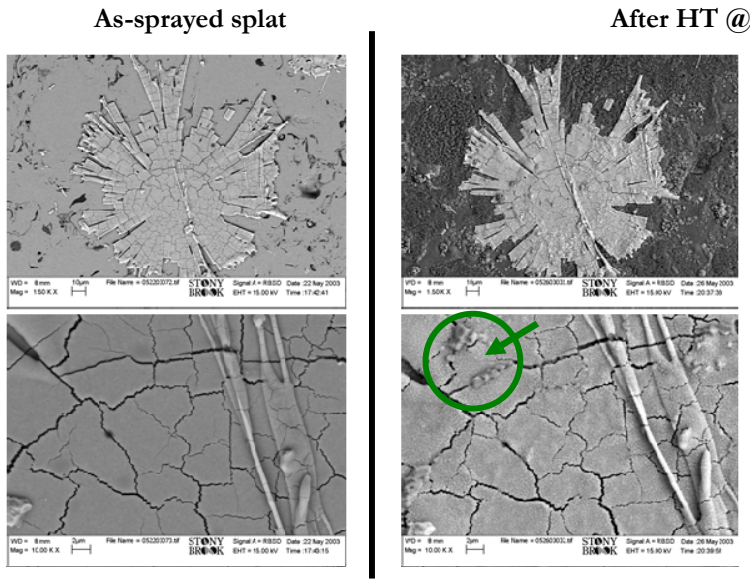

Outward oxide growth from bond coat oxide as seen on top surface (green arrow)
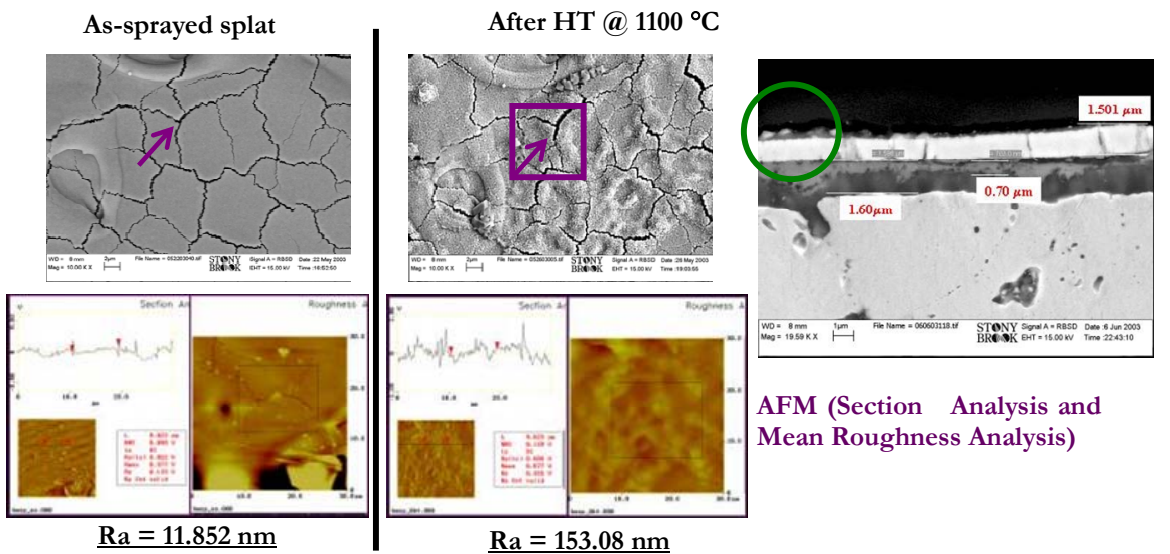

(b) 

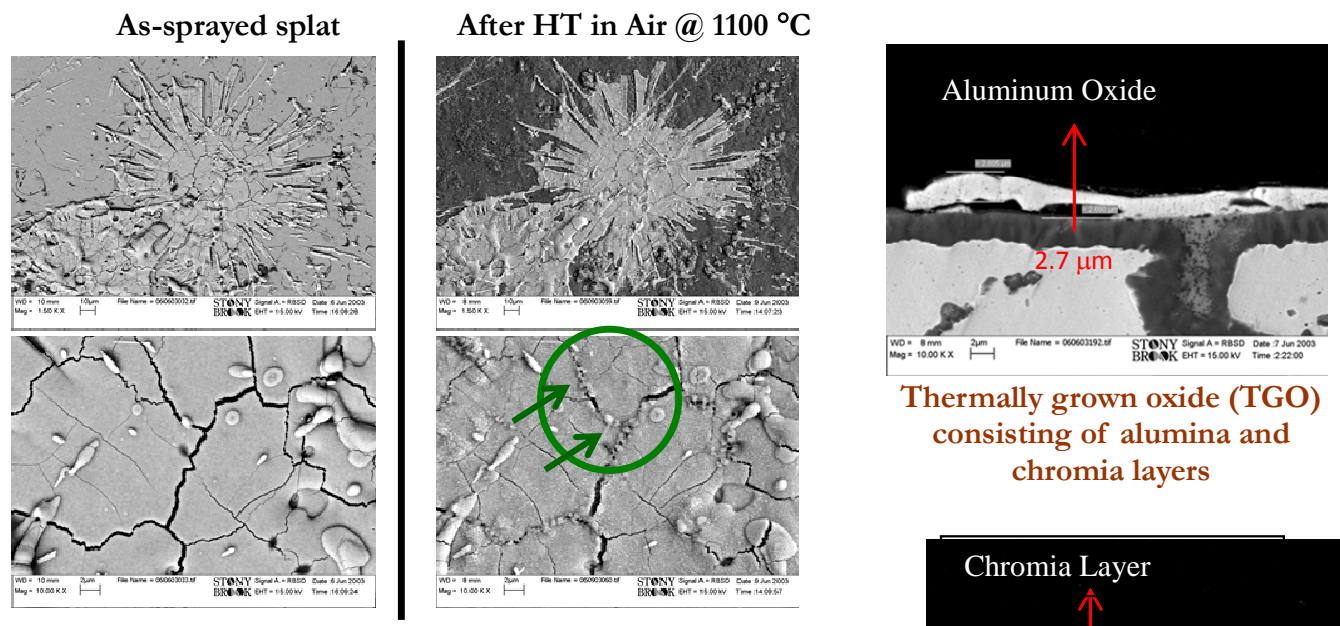

Thermally grown oxide (TGO)

consisting of alumina and chromia layers

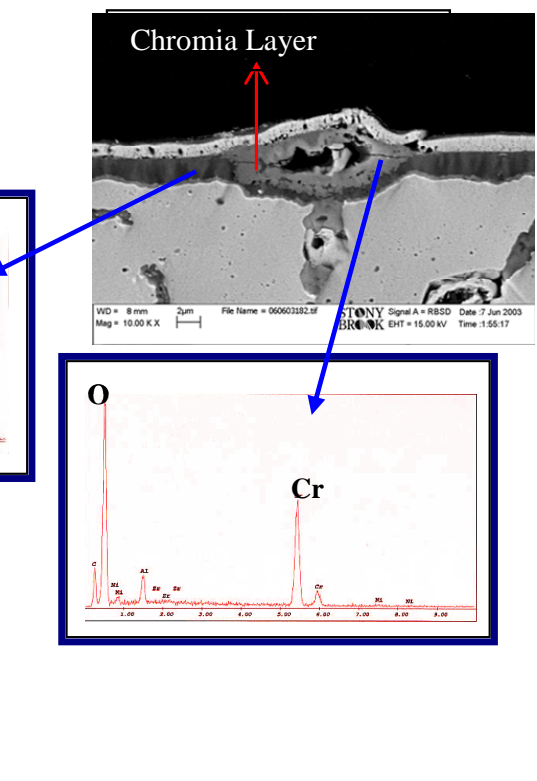

(c)

Figure 7. (a) Splat exposed for 2 hr; (b) Splat exposed for 8 hr; (c) Splat exposed for 24 hr.

TGO layer is mainly constituted by Alumina since $\mathrm{Al}$ in the bond coat is preferably oxidized but at some places Chromia is also formed as disclosed by EDS. Previous studies also show that other oxides occur in isolated domains within the TBC next to the TGO and have a lighter gray contrast. These are typically spinels comprising oxides of $\mathrm{Cr} / \mathrm{Ni} / \mathrm{Co}$ often with associated internal porosity [11]. Studies have shown that spinels when formed also act as preferential sites for failure [11]. Reason might be that the interfacial fracture resistances of the TBC/ $\alpha$-chromia and the TBC/spinel interfaces are lower than that of the $\mathrm{TBC} / \alpha$-alumina interface originally present [12].

Thickness imperfections in TGO enlarge in regions where O2-diffusivity through TGO is exceptionally large i.e. at locations where TGO contains oxides other than alumina [8]. These TGO undulations must then push the grains in the splats upward and cause splat lifting or may be spalling. This explains the increase of surface roughness.

\subsection{Elimination of Bond Coat Oxidation-Effect of Heat Treatment Environment}

In order to isolate the effect of bond coat oxidation, heat treatment was conducted in vacuum thus eliminating it. Thermal cycling studies of TBC systems have shown how bond coat oxidation leads to phenomena such as ratcheting and influences TBC behavior and failure [5-9]. The role of the TGO layer that grows between bond coat and TBC during thermal cycling is of significance. In order to assess this, heat treatments were also conducted in vacuum so as to eliminate oxidation and see how the behavior differs with changes in HT environment.

Figure 8 shows an as-sprayed YSZ splat subjected to an intermediate vacuum heat treatment at $1100^{\circ} \mathrm{C}$ for 2 hrs before exposure to the $24 \mathrm{hr}$ air $\mathrm{HT}$ at $1100^{\circ} \mathrm{C}$. After 

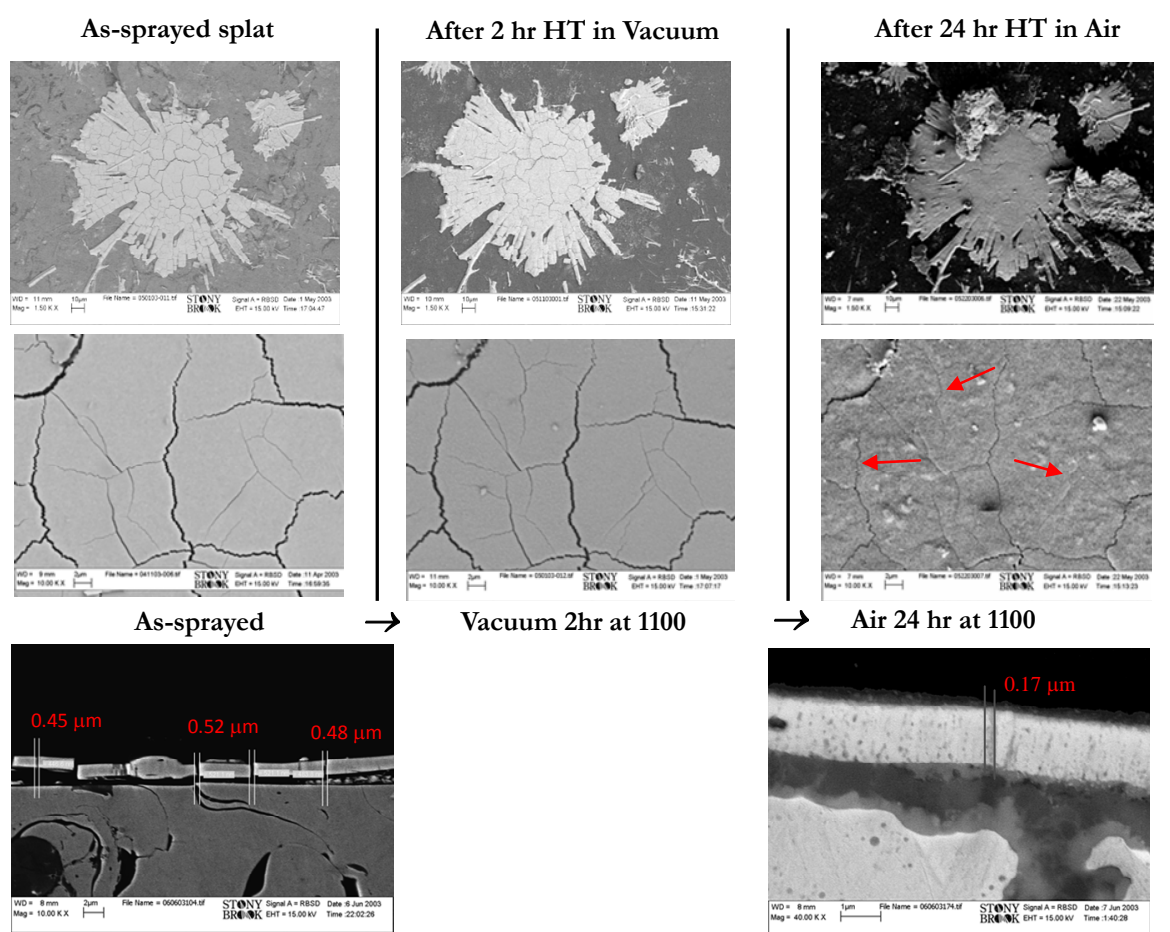

Figure 8. As-sprayed splat $\rightarrow$ exposed for 2 hr in Vac $\rightarrow$ exposed for 24 hr @ $1100 \mathrm{C}$ in air.

the intermediate vacuum $\mathrm{HT}$ of $2 \mathrm{hr}$ at $1100^{\circ} \mathrm{C}$, the overall microcrack network appears unaltered as seen in the top surface microstructures. The oxide grain growth through microcracks or the splat surface roughening are however, not visible.

A comparison is made between this and the as-sprayed splat that directly underwent the $24 \mathrm{hr}$ air HT, as shown in Figure 7(c). As discussed earlier in section 3.2, the splats directly exposed to the $24 \mathrm{hr}$ Air $\mathrm{HT}$ at $1100^{\circ} \mathrm{C}$ showed instances of outward oxide growth through microcracks (circle marks) and surface roughening due to splat lifting (square marks).

However, the splats with intermediate vacuum HT as shown in Figure 8 when thermally treated in air for $24 \mathrm{hr}$ showed no signs of grain growth through microcracks or of upward lifting of grains. Additionally, most fine microcracks are seen to have sintered as marked by arrows. The cross-section images show that microcrack widths are much reduced compared to the as-sprayed splat. TGO growth does occur in the subsequent air HT but the outward oxide growth is curtailed probably because the intermediate vacuum treatment started the sintering or sealing of most microcracks from their bottom end. This may be related to the increase in lattice spacing that was observed by Thornton et al. [13] when a TBC coating was heat treated in vacuum. In vacuum, there is no oxygen to replace that lost from zirconia in the formation of bond coat oxide and less oxygen appears to cause larger lattice spacing [13].

Thus the overall sintering behavior is notably altered by a change in heat treatment environment.

\section{Summary and Conclusions}

The high temperature behavior of a TBC system is investigated using single splats of YSZ on MCrAlY bond coat surface instead of freestanding thick YSZ coatings, in order to integrate the effects of splat-substrate interfacial interaction and bond coat oxidation at a fundamental level. In case of single splats sprayed on polished bondcoat surface, there are no preexisting undulations (interfacial imperfections), and also no influence of thick top coating. Phenomena such as ratcheting and rumpling which have been analyzed in other studies with thick topcoats are not observed here. These would have drastic spallation effects in case of single splats and hence have been excluded by the usage of polished bond coat surface and short thermal exposures. Effects of thermal treatment are attributable to the thickening of the thermally grown oxide (TGO) layer and the initial bond coat microstructure.

- The TGO layer grows and thickens with increasing temperature and duration of thermal exposure. Thermal treatment temperature is seen to have a more significant influence on microcracks sintering than the duration of thermal exposure.

- Environment during thermal exposure also has a re- 
markable impact. Even a short intermediate vacuum treatment changes the high temperature behavior observed otherwise during long air treatment and causes sintering of most fine microcracks. Thus sintering of microcracks is directly influenced by bond coat oxidation.

- Microcracks in as-sprayed splats coincide with internal oxide positions within bond coat. A path is thus provided for oxygen to reach a bond coat area that is locally depleted of aluminum. As such, other oxides such as NiO form locally at these microcracks. Chemical changes occur in the bond coat oxidation due to presence of the YSZ splats on top.

- Outward oxide growth into microcracks increases with heat treatment temperature as well as time.

- Longer thermal treatment durations cause further $\mathrm{Al}$ depletion within bond coat leading to formation of oxides other than $\alpha$-alumina in the TGO, thereby creating thickness imperfections in the TGO at some locations. These TGO undulations are observed to push grains in the splats upward and induce splat lifting/spalling. Interaction between evolving TGO and YSZ top coat is thus apparent in the form of splat surface roughening.

The distinctions of TGO formation and interactions with YSZ as a function of initial YSZ splat layer (morphology, purity) and initial bond coat microstructure (processing conditions) will be addressed in a subsequent paper.

\section{Acknowledgements}

We would like to thank Glenn Bancke, AnirudhaVaidya and $\mathrm{Li} \mathrm{Li} \mathrm{(CTSR)} \mathrm{for} \mathrm{preparation} \mathrm{of} \mathrm{the} \mathrm{specimens} \mathrm{and}$ spraying diagnostics.

\section{REFERENCES}

[1] P. S. Mohanty, "Challenges in Thermal Spraying of Refractory Materials,” Surface Engineering, Vol. 21, No. 1, 2005, pp. 1-4. doi:10.1179/174329405X36691

[2] A. G. Evans, "Thermal Barrier Coatings: Workshop Summary,” TBC Workshop, Irsee, 17-22 August 2003, pp. 1722.

[3] A. N. Khan and J. Lu, "Behavior of Air Plasma Sprayed Thermal Barrier Coatings, Subject to Intense Thermal Cycling," Surface and Coatings Technology, Vol. 166, No. 1, 2003, pp. 37-43. doi:10.1016/S0257-8972(02)00740-5
[4] T. Xu, M. Y. He and A. G. Evans, "A Numerical Assessment of the durability of Thermal Barrier Systems That Fail by Ratcheting of the Thermally Grown Oxide," Acta Materialia, Vol. 51, No. 13, 2003, pp. 3807-3820. doi:10.1016/S1359-6454(03)00194-0

[5] A. M. Karlsson, J. W. Hutchinson and A. G. Evans, “The Displacement of the Thermally Grown Oxide in Thermal Barrier Systems upon Thermal Cycling," Materials Science and Engineering, Vol. 351, No. 1-2, 2003, pp. 244 257. doi:10.1016/S0921-5093(02)00843-2

[6] M. Y. He, A. G. Evans and J. W. Hutchinson, “The Ratcheting of Compressed Thermally Grown Thin Films on Ductile Substrates,” Acta Materialia, Vol. 48, No. 10, 2000, pp. 2593-2601. doi:10.1016/S1359-6454(00)00053-7

[7] D. R. Mumm, A. G. Evans and I. T. Spitsberg, "Characterization of a Cyclic Displacement Instability for a Thermally Grown Oxide in a Thermal Barrier System," Acta Materialia, Vol. 49, No. 12, 2001, pp. 2329-2340. doi:10.1016/S1359-6454(01)00071-4

[8] A. G. Evans, D. R. Mumm, J. W. Hutchinson, G. H. Meier and F. S. Pettit, "Mechanisms Controlling the Du- rability of Thermal Barrier Coatings," Progress in Materials Science, Vol. 46, No. 5, 2001, pp. 505-553. doi:10.1016/S0079-6425(00)00020-7

[9] R. Panat, S. Zhang and K. J. Hsia, "Bond Coat Surface Rumpling in Thermal Barrier Coatings," Acta Materialia, Vol. 51, No. 1, 2003, pp. 239-249. doi:10.1016/S1359-6454(02)00395-6

[10] A. M. Karlsson and A. G. Evans, "A Numerical Model for the Cyclic Instability of Thermally Grown Oxides in Thermal Barrier Systems," Acta Materialia, Vol. 49, No. 10, 2001, pp. 1793-1804. doi:10.1016/S1359-6454(01)00073-8

[11] A. Rabiei and A. G. Evans, "Failure Mechanisms Associated with the Thermally Grown Oxide in Plasma Sprayed Thermal Barrier Coatings," Acta Materialia, Vol. 48, No. 15, 2000, pp. 3963-3976. doi:10.1016/S1359-6454(00)00171-3

[12] E. A. G. Shillington and D. R. Clarke, "Spalling Failure of a Thermal Barrier Coating Associated with Aluminum Depletion in the Bond-Coat," Acta Materialia, Vol. 47, No. 4, 1999, pp. 1297-1305. doi:10.1016/S1359-6454(98)00407-8

[13] J. Thornton, D. Cookson and E. Prescott, "The Measurement of Strains within the Bulk of Aged and As-Sprayed Thermal Barrier Coatings Using Synchrotron Radiation," Surface and Coatings Technology, Vol. 120-121, 1999, 96-102. doi:10.1016/S0257-8972(99)00340-0 